\title{
ХИРУРГИЯ
}

УДК 617-089.844

Н. С. Романенков ${ }^{1}$, К. Н. Мовчан ${ }^{1,2}$

НЕГАТИВНЫЕ ЭФФЕКТЫ ТРАНСПЛАНТАЦИИ

АУТОЛОГИЧНОЙ ЖИРОВОЙ ТКАНИ, ОБОГАЩЕННОЙ КУЛЬТУРОЙ СТВОЛОВЫХ КЛЕТОК (ОБЗОР ЛИТЕРАТУРЫ)

\footnotetext{
${ }^{1}$ Медицинский информационно-аналитический центр, Российская Федерация, 198095, Санкт-Петербург, ул. Шкапина, 30, лит. А

${ }^{2}$ Северо-Западный государственный медицинский университет им. И. И. Мечникова, Российская Федерация, 191015, Санкт-Петербург, ул. Кирочная, 41
}

Представлены сведения специалистов в области пластической, реконструктивной и эстетической хирургии, исследовавших риски развития и структуру осложнений клеточной терапии на этапе как сбора биологического материала для выделения стволовых клеток, так и их последующей трансплантации. Анализ данных многих авторов позволяет считать, что даже при минимальной инвазивности хирургических вмешательств на этапах осуществления клеточно-связанного липотрансфера выполнение этих операций все же сопряжено с возможностью развития ряда осложнений, в том числе и при их осуществлении соматически здоровым пациентам по эстетическим показаниям. Частота развития осложнений, представляющих угрозу для жизни, при клеточно-связанном липотрансфере варьирует от 0,02 до 0,3\%. Очевидно, что проведение хирургических вмешательств в формате клеточной терапии должно осуществляться исключительно по показаниям с учетом данных клинического обследования пациентов до трансплантации стволовых клеток. Для предупреждения осложнений клеточносвязанного липотрансфера в послеоперационном периоде необходимо скрупулезное соблюдение правил асептики и антисептики, методики выполнения хирургических вмешательств, комплексной профилактики (независимо от объема операции) тромботических осложнений, целенаправленной компенсационной коррекции сопутствующей патологии пациента. Библиогр. 70 назв.

Ключевые слова: пластическая хирургия, осложнения операций, мезенхимальные стволовые клетки, жировая ткань.

\section{ADIPOSE DERIVED STEM CELLS TRANSPLANTATION NEGATIVE EFFECTS (REVIEW)}

N.S. Romanenkov ${ }^{1}$, K. N. Movchan ${ }^{1,2}$

${ }^{1}$ St. Petersburg Medical informational analytic center, 30, lit. A, ul. Shkapina, St. Petersburg, 198095, Russian Federation

${ }^{2}$ North-West State Medical University named after I. I. Mechnikov, 41, ul. Kirochnaya, St. Petersburg, 191015, Russian Federation

The data here represents those of specialists in plastic, reconstructive and aesthetic surgery who investigated the risks of development and structure of cell therapy-associated complications, both at the

(c) Санкт-Петербургский государственный университет, 2017 
stage of collecting biological material for stem cells (SC) isolation and their subsequent transplantation. Data analysis suggests that even in minimally invasive surgical procedures during cell-associated lipotransfer $(\mathrm{CAL})$, these surgeries are still fraught with risks of complications even in cases of somatically healthy patients for aesthetic indications. The incidence of life-threatening complications of CAL varies from $0.02 \%$ to $0.3 \%$. It is clear that CAL-surgery must be carried out exclusively on the testimony based on the data of clinical examination of patients before SC transplantation. To prevent CAL complications in the postoperative period, the rules of aseptic and antiseptic, comprehensive thrombotic events prevention (irrespective of surgery), targeted compensatory adjustment of concomitant pathology of the patient must be scrupulously observed. Refs 70 .

Keywords: plastic surgery, surgery complications, mesenchymal stem cells, adipose tissue.

\section{Введение}

На протяжении всей истории цивилизации разрабатываются и совершенствуются методики коррекции дефектов человеческого тела. В этом отношении особая роль принадлежит пластической хирургии. Ее становление и развитие не всегда сопровождалось благоприятными исходами операций. В 1921 г. впервые по эстетическим показаниям была выполнена липосакция (ЛС), направленная на коррекцию формы голеней. Течение послеоперационного периода осложнилось некрозом кожи, затем гангреной оперированной конечности, что обусловило необходимость ее ампутации [1].

В 1983 г. впервые было предложено применять при липосакции тупоконечные канюли [2]. В сообщении о позитивных в целом результатах выполнения более 3000 липоаспираций, основанном на результатах наблюдения за пациентами в послеоперационном периоде, среди прочего приведены данные об основных опасностях и осложнениях при проведении ЛС [2]. В современной хирургической практике липосакция является одной из наиболее часто выполняемых косметических операций при разных аппаратных методиках ее проведения [3; 4].

Важным побудительным событием для дальнейшего развития трансплантации аутологичной жировой ткани (АЖТ), в том числе и по эстетическим показаниям, оказалось открытие в 2001 г. мезенхимальных стволовых клеток (СК), выделенных из АЖТ [5], а в качестве основной методики забора биологического материала для выделения культуры СК стала использоваться именно ЛС.

Фундаментальные исследования уникальных регенеративных свойств СК, полученных из АЖТ, позволили в 2008 г. внедрить в клиническую практику клеточно-связанный липотрансфер (КСЛ) - методику, посредством которой можно увеличить объем трансплантируемой жировой ткани при одновременной минимизации негативных последствий выполнения хирургического вмешательства [6].

Как правило, авторы сообщают о положительных результатах применения КСЛ в клинической практике [7-10]. Для целенаправленного внедрения новых технологий клеточной терапии в повседневную деятельность прежде всего необходимо выявить их потенциальные риски и осложнения; поэтому требуется критически проанализировать опыт исследователей, специально изучавших данные аспекты медицинской деятельности. 


\section{Материалы и методы исследования}

Негативные последствия, сопряженные с проведением КСЛ как на этапе сбора биологического материала для выделения СК, так и на этапе последующей аутоадипотрансплантации могут обусловливать инвалидизацию и представлять опасность для жизни для практически здоровых людей. Без изучения результатов реализации базисных мероприятий по профилактике осложнений КСЛ в ближайшем и отдаленном послеоперационном периодах данное направление пластической хирургии невозможно в плане его научного обоснования.

Основная цель проведенной работы - оценка сведений многих исследователей, занимающихся изучением возможностей клинического применения СК из ЖТ, о безопасности проведения КСЛ на всех этапах его выполнения. Особым побудительным мотивом для сбора, обработки и анализа данных источников научной литературы оказывается противоречивость сведений исследователей, целенаправленно занимающихся изучением проблем клеточной хирургии с позиций применения ее технологий в рамках регенеративной медицины.

\section{Результаты исследования и их обсуждение}

Клиническое применение стволовых клеток из жировой ткани технологически проводится в несколько этапов: 1) сбор биологического материала для выделения СК, осуществляемый, как правило, путем липосакции; 2) непосредственное выделение культуры СК из АЖТ; 3) обогащение трансплантируемой жировой ткани СК, ее имплантация в зону дефицита мягких тканей человеческого организма при липофилинге [7-10]. Негативные последствия клинического применения СК из ЖТ в пластической и реконструктивной хирургии могут возникнуть на любом из этапов. По существующим данным [11], в настоящее время компетентными исследователями опубликовано около двух десятков статей, в которых сообщается почти о 400 случаях выполнения КСЛ преимущественно с целью коррекции формы и объема молочных желез, устранения деформаций мягких тканей лица. Анализ содержания публикаций показывает, что о каких-либо послеоперационных осложнениях авторы не сообщают. Последнее, вероятно, связано с относительно небольшим числом клинических наблюдений, а также тщательным соблюдением авторами технологий выполнения данного хирургического вмешательства [11].

Технологии регенеративной медицины в плане клеточной терапии пока не являются рутинными манипуляциями, однако уже сегодня некоторыми специалистами в области пластической и реконструктивной хирургии избирательно применяются для коррекции дефектов мягких тканей тела человека, а также для лечения осложнений тяжелых соматических заболеваний (ишемическая болезнь сердца, сахарный диабет, облитерирующий атеросклероз сосудов нижних конечностей). В целом ЛС и липофилинг - неотъемлемые части этапов применения клеточных технологий в пластической и реконструктивной хирургии. В то же время данные, публикуемые исследователями, не позволяют прийти к выводу, что липосакция и липофилинг являются абсолютно безопасными хирургическими вмешательствами. Риск развития осложнений в послеоперационном периоде сохраняется даже при выполнении подобных операций соматически здоровым пациентам. 


\section{I. Негативные последствия выполнения липосакиии}

Липосакция (ЛС) - одна из наиболее распространенных в мире эстетических операций. Тенденция к увеличению частоты ее выполнения сохраняется, поэтому нельзя не учитывать мнение авторов, сообщающих о потенциальных осложнениях ЛС как одного из этапов КСЛ $[12 ; 13]$.

В частности, приводятся данные о том, что большинство специалистов, считая ЛС минимально инвазивным и относительно безопасным вмешательством, выполняют данную операцию преимущественно амбулаторно, при этом риски, связанные с операцией, особенно в случаях ее проведения для получения АЖТ с целью выделения из нее СК, часто недооцениваются пластическими хирургами [12]. Показатели общей частоты осложнений ЛС, по данным разных авторов, варьируются от 8,6 до $20 \%$. Наиболее частыми компликациями ЛС оказываются: неоднородность контура поверхности тела (до 20 \% клинических наблюдений), формирование сером, гиперпигментация кожи в зоне удаления избытка жировой ткани, различные виды асимметрии формы тела и развитие гипертрофических рубцов в местах введения канюль $[13 ; 14]$.

Летальные исходы, обусловленные выполнением ЛС, возникающие по причине таких ее осложнений, как некроз кожи, развитие генерализованных бактериальных инфекций, некротизирующего фасциита (НФ), тромбоэмболии легочной артерии (ТЭЛА), тромбоза глубоких вен нижних конечностей, констатируются в $0,02-0,25 \%$ случаев [13; 15-17]. Показатель послеоперационной летальности при выполнении ЛС составляет 1 случай на 5000 вмешательств [15].

Таким образом, несмотря на относительную безопасность и минимальную инвазивность ЛС, выполнение этой операции так же, как и других хирургических вмешательств, все же сопряжено с вероятностью развития ряда осложнений. Общая частота компликаций при выполнении липосакции достигает $20 \%$ всех клинических наблюдений, при этом фатальные осложнения данного хирургического вмешательства происходят в $0,25 \%$ случаев.

1. Интраоперационные осложнения липосакции

А. Ранения передней брюшной стенки и органов брюшной полости

Несмотря на то что при ЛС инструменты вводятся хирургом не глубже подкожного слоя передней брюшной стенки, изменение угла введения канюли устройства в жировую ткань в сочетании с анатомическими особенностями пациента в отдельных случаях может способствовать повреждению более глубоких структур (мышц передней брюшной стенки, органов брюшной полости и др.) [3]. Повреждение мышц передней брюшной стенки может в последующем обусловливать формирование грыжевых ворот с образованием в конечном итоге абдоминальной грыжи.

Ряд авторов сообщает о случаях проникающих ранений живота при выполнении ЛС передней брюшной стенки по эстетическим показаниям [18-21]. В частности, во время ЛС могут повреждаться стенки кишок, что обусловливает развитие перитонита, а в отдельных случаях - абдоминального сепсиса. Ранение передней брюшной стенки или кишечника во время ЛС является второй (после тромботических осложнений) наиболее распространенной причиной летальных исходов при проведении данной операции [2; 22]. Некоторые авторы сообщают о повреждениях 
других внутренних органов, таких как желчный пузырь, поджелудочная железа и селезенка $[12 ; 14]$.

Представлены данные о случае успешного лечения распространенного перитонита, развившегося у 52-летней пациентки после выполнения ей ЛС передней брюшной стенки [23]. Симптомы неблагополучия в брюшной полости у больной стали определяться в течение 48 часов после ЛС (вздутие живота, рвота, отсутствие стула). Врачом клиники, в которой проводилась операция, было рекомендовано увеличить дозы анальгетиков. На четвертые сутки после операции диагностирован инфекционно-токсический шок, абдоминальный сепсис. Больную госпитализировали в отделение интенсивной терапии общехирургического стационара. После краткосрочной предоперационной подготовки, направленной на стабилизацию витальных функций, выполнена лапаротомия. При ревизии брюшной полости выявлены ранения тонкой и толстой кишок, частичный некроз прямой мышцы живота справа, признаки разлитого гнойно-фибринозного перитонита. Выполнены резекция тонкой кишки, ушивание ран толстой кишки, санация и дренирование брюшной полости. Пациентка находилась в отделении реанимации и интенсивной терапии в течение трех недель. При ее лечении осуществлялись этапные санационные лапаротомии, во время одной из которых выполнена резекция участка кишки с формированием еюно- и колостомы. Непрерывность кишечника восстановлена через 10 месяцев. В дальнейшем больной выполнен ряд реконструктивных операций на передней брюшной стенке с положительным исходом.

Отдельного внимания заслуживают случаи осложнений липосакции, выполняемой по эстетическим показаниям. Так, сообщается о пациенте, обратившемся в приемное отделение общехирургического стационара через семь дней после ЛС [24]. При осмотре в приемном отделении больной жаловался на поступление калового отделяемого из раны передней брюшной стенки (ПБС). При КТ живота выявлен абсцесс ПБС, сформировавшийся толстокишечный свищ, полностью закрывшийся после устранения абсцесса.

В целом случаи перфорации передней брюшной стенки и ранение органов брюшной полости при выполнении ЛС, по данным разных авторов, оказываются крайне трудными для ранней диагностики, поскольку клинические проявления развившегося неблагополучия в брюшной полости маскируются болевым синдромом после перенесенной липосакции и до определенного времени нивелируются пероральным приемом обезболивающих препаратов. Вероятно, по этим же причинам в большинстве случаев повреждения органов брюшной полости при выполнении ЛС диагностируются хирургами общего профиля часто по прошествии более 24 часов с момента выполнения первичной эстетической операции.

Повреждения внутренних органов при ЛС не всегда связаны с техническими дефектами ее выполнения. Не последнюю роль в развитии данных осложнений операций могут играть анатомические особенности строения тела пациента. Для своевременного выявления таких опасных осложнений липосакции, как повреждение внутренних органов, пластический хирург, выполняющий данную операцию, обязан обладать достаточными знаниями неотложной хирургии грудной и брюшной полостей. Он должен своевременно заподозрить и диагностировать осложнение, развившееся у пациента, и выполнить хирургическое вмешательство, направленное на его устранение. 


\section{В. Повреждения кровеносных и лимфатических сосудов}

Повреждение кровеносных сосудов малого диаметра при ЛС происходит неизбежно. Вероятность интенсивного кровотечения при этом невелика, т. к. оно успешно предотвращается предоперационной инфильтрацией подкожной жировой клетчатки при помощи раствора, содержащего сосудосуживающие препараты, а также использования компрессионного трикотажа в послеоперационном периоде [14]. При отсутствии тщательного гемостаза в процессе операции или не выявленных перед операцией коагулопатиях после ЛС в области хирургического вмешательства может сформироваться гематома [3; 25]. Формирование сером оказывается вторым наиболее частым осложнением после ЛС (2,3-3,5\% наблюдений). Причиной их формирования после хирургического вмешательства, как правило, является интраоперационное повреждение мелких лимфатических сосудов [13]. По этой же причине выполнение ЛС передней брюшной стенки, лонной области может способствовать формированию лимфатического отека мошонки или больших половых губ [26]. В большинстве случаев с проявлениями лимфатического отека и серомами удается справиться, применяя компрессионный трикотаж, лимфодренажный массаж, однако при отсутствии положительного эффекта от консервативного лечения может потребоваться дренирование сформировавшейся полости [26].

С. Инфекционные осложнения в области хирургического вмещательства при типосакции

Поскольку во время ЛС в определенной мере происходит разрушение жировой ткани в зоне ее выполнения, формирующаяся биологическая среда оказывается благоприятной для жизнедеятельности и размножения микроорганизмов. При отсутствии должного контроля за соблюдением правил асептики и антисептики в зоне хирургического вмешательства могут развиться различные формы гнойновоспалительных явлений - от поверхностной флегмоны до некротизирующего фасциита (НФ), являющегося жизнеугрожающим состоянием [27].

Наиболее частыми возбудителями инфекций в зоне хирургического вмешательства при ЛС оказываются бактерии (различные виды стрептококков, анаэробные и факультативные анаэробные бактерии) [28; 29], констатируются спорадические случаи инфекций, вызванных микобактериями (Муcobacterium chelonae, M. fortuitum и M. abscessus) [30-32]. В ряде публикаций авторы сообщают о случаях возникновения локальной инфекции в области хирургического вмешательства, сопряженной с контаминацией раны M. fortuitum и M. abscessus [33].

При поверхностной флегмоне в области выполнения ЛС гнойно-воспалительный процесс локализуется в подкожной жировой клетчатке. Клинический диагноз, как правило, основывается на явлениях лихорадки, локальной гипертермии, гиперемии, повышении интенсивности болевого синдрома в послеоперационном периоде, результатах анализа крови (повышение уровня С-реактивного белка и лейкоцитов), а также на характерных КТ-признаках (отек глубоких слоев дермы, фасций, признаки регионарного лимфаденита) [34-36].

Редким, но часто фатальным осложнением ЛС является НФ - распространенный гнойно-некротический процесс, поражающий подкожную клетчатку, глубокую фасцию и подлежащие ткани. Случаи данного осложнения не являются рутинными в практике пластического хирурга, однако развитие данной компликации часто оказывается сопряжено с крайне высоким (до 50 \%) риском летального 
исхода [37-44]. Одним из наиболее точных методов верификации НФ оказывается КТ, а основным критерием, отличающим НФ от поверхностной флегмоны, является наличие пузырьков воздуха в подлежащий мышцах [45]. В случаях диагностики у пациента НФ методом выбора является радикальная некрэктомия с адекватной антибактериальной терапией при оптимальном режиме инфузий [46].

Предотвращение инфекции в области хирургического вмешательства в послеоперационном периоде, в том числе и при ЛС, - проблема медицины. Поскольку пластические и реконструктивные операции с применением клеточных технологий, как правило, проводятся пациентам на фоне существующей коморбидной патологии, развитие гнойно-воспалительных явлений в области операционной раны нельзя расценивать иначе, как неудовлетворительный результат КСЛ, обусловливающий ухудшение качества жизни пациента и нерациональное использование специализированных ресурсов здравоохранения. Для предотвращения таких осложнений необходимо строгое соблюдение правил асептики на всех этапах пребывания пациента в клинике, проведение предоперационной антибиотикопрофилактики гнойно-воспалительных компликаций таким пациентам даже при минимальных вмешательствах.

2. Внеопе рационные осложнения липосакции

Тромботические состояния - одно из наиболее распространенных осложнений, наблюдаемых после ЛС. Общая частота развития тромбоза глубоких вен нижних конечностей у пациентов на фоне профилактики после общехирургических операций варьируется от 3 до $20 \%$ [47]. В сравнении с этими данными ТЭЛА или тромбоз глубоких вен нижних конечностей после ЛС, выполненной пациентам по эстетическим показаниям, происходит менее чем в $1 \%$ случаев. Однако на долю этих осложнений приходится более $20 \%$ случаев летальности в послеоперационном периоде (наиболее частая причина смерти после липосакции) [48]. Патогенетические механизмы венозной тромбоэмболии после липосакции включают в себя повреждение сосудов во время операции, повышение вязкости крови, вызванное гиповолемией, замедление скорости кровотока по причине длительного вынужденного положения пациента на операционном столе [49]. По этим причинам к особенностям профилактики тромботических осложнений при ЛС авторы в первую очередь относят предупреждение аспирации большого объема жировой ткани и уменьшение длительности проведения операции [50].

Одним из эффективных методов лечения тромбоэмболии крупных ветвей легочной артерии при своевременной ее диагностике оказывается выполнение тромбэктомии по экстренным показаниям с проведением антикоагулянтной терапии в послеоперационном периоде. В частности, сообщается об успешном удалении тромба из легочной артерии в случае лечения больной с массивной ТЭЛА, развившейся через семь недель после абдоминопластики в сочетании с липосакцией передней брюшной стенки [51]. Пациентка выписана из клиники в удовлетворительном состоянии на седьмые сутки после проведенной ей тромбэктомии.

Таким образом, тромботические осложнения при выполнении липосакции являются редкими, но часто фатальными компликациями данного хирургического вмешательства. Тромботические осложнения могут произойти при выполнении любой операции, проводимой в условиях общего обезболивания. Разработка способов их профилактики остается актуальной задачей медицинской науки. В на- 
стоящее время сформулированы стандарты предоперационной профилактики тромботических осложнений, обязательные для применения специалистами всех хирургических специальностей. Неоспоримым фактом является необходимость всестороннего предоперационного обследования пациента, особенно перед плановыми хирургическими вмешательствами, в том числе и при трансплантации АЖТ, обогащенной культурой СК. Для профилактики ТЭЛА при выполнении ЛС, в том числе и с целью сбора АЖТ для выделения из нее СК, необходимо применять компрессионный трикотаж в ходе вмешательства, способствовать ранней активизации пациента, вводить препараты низкомолекулярных гепаринов в послеоперационном периоде, одномоментно аспирировать не более 1500 мл жировой ткани [12]. Данный подход позволяет минимизировать риск возникновения тромботических осложнений.

Таким образом, несмотря на то что ЛС относится к технологиям миниинвазивной хирургии, нельзя не признать, что ее проведение может быть сопряжено с развитием осложнений, представляющих опасность для жизни, - тяжелых гнойно-воспалительных процессов в области хирургического вмешательства, ранений передней брюшной стенки и органов полости брюшины, кровотечений в послеоперационном периоде, тромботических осложнений. Характер осложнений может варьироваться от диспептических явлений, легко купируемых медикаментозно, до необратимых социальных последствий, включая инвалидизацию пациентов и их смерть.

\section{II. Негативные последствия выделения культуры стволовых клеток из жировой ткани}

Выделение культуры СК из аутологичной жировой ткани - отработанная медицинская технология. Однако для ее успешного осуществления и получения из собранного биологического материала элементов клеточной культуры надлежащего количества требуются специальные знания и соблюдение ряда технологических особенностей [52-62].

На свойства выделяемых СК оказывают влияние возраст пациентов, характер сопутствующих соматических заболеваний, анатомо-физиологические особенности донорской зоны, используемой для получения жировой ткани [52; 53]. В частности, доказано, что в жировой ткани больных сахарным диабетом, в отличие от здоровых людей, содержится меньшее количество СК, которые к тому же характеризуются пониженным профилем фенотипической экспрессии и способностью к пролиферации [54].

На число и жизнеспособность СК, получаемых из ЖТ, в значительной степени оказывает влияние методика проведения ЛС. При классической ЛС повышение уровня отрицательного давления в аспираторе может негативно сказаться на количестве выделяемых полипотентных клеток [55].

Согласно рекомендациям, выработанным в 2007 г., липоаспират при извлечении из него СК должен обрабатываться в первые сутки после экстракции биоматериала из организма, поскольку хранение жирового субстрата, изымаемого при ЛС, в условиях комнатной температуры сопряжено с уменьшением потенции СК к выживаемости [56].

Для снижения вероятности микробной контаминации биологического материала, исключения возможности тканевых (неклеточных) загрязнений сформиро- 
ванного биологического субстрата жировой слой, оставшийся в ходе выделения культуры СК, промывается стерильным раствором фосфатного буфера с добавлением антибактериальных и противомикотических средств [57; 58].

После промывания ЖТ ферментируется стерильным раствором коллагеназы с целью освобождения компонентов стромальной сосудистой фракции (ССФ), содержащей СК [59]. Особое внимание при выделении СК из ЖТ авторы уделяют определению оптимальных сроков ферментативного воздействия на липоаспират, поскольку чрезмерное превышение длительности этого процесса может привести к разрушению клеточной культуры СК. Ряд исследователей рекомендует ферментировать липоаспират в течение 1-2 часов [60]. Существует мнение, что ферментативное расщепление ЖТ до однородного вида липоаспирата при температуре $37^{\circ} \mathrm{C}$ в течение двух часов обеспечивает наилучший баланс между степенью диссоциации исходного биологического материала и количеством получаемых СК [61].

По завершении ферментативного расщепления липоаспирата осуществляется центрифугирование компонентов ССФ до полной изоляции СКЖТ. Физические эффекты центрифугирования так же, как и параметры давления при вакуумной липосакции, могут негативно влиять на жизнеспособность и количество СКЖТ, используемых в итоге для культивирования [62].

\section{III. Осложнения липофилинга}

Основной методикой трансплантации АЖТ, обогащенной культурой СК, является липофилинг (ЛФ) или КСЛ. Эта операция считается относительно безопасным хирургическим вмешательством, выполняемым пластическими хирургами, в том числе и по эстетическим показаниям для коррекции дефицита объема мягких тканей разных анатомических локализаций. При анализе научных публикаций многих исследователей обращает на себя внимание отсутствие сообщений об осложнениях трансплантации АЖТ, обогащенной культурой СК, выделенных из нее. Данное обстоятельство косвенно может свидетельствовать как об относительной безопасности данной операции, так и о малом опыте выполнения подобных манипуляций специалистами. В то же время некоторые авторы приводят данные об осложнениях липофилинга - базисной манипуляции при трансплантации АЖТ.

К негативным последствиям ЛФ относятся случаи летального исхода, острого нарушения мозгового кровообращения, потери зрения, инфекции в области хирургического вмешательства, формирования гигантских некротических жировых кист [63-70]. Так, группа исследователей, проведя в 2015 г. метаанализ, сообщила, что угрожающие жизни осложнения при выполнении липофилинга развиваются в 3,5\% случаев, а общая летальность после выполнения данной манипуляции составляет 0,3\% [63].

В настоящее время ЛФ часто применяется по косметическим показаниям для коррекции возрастных инволютивных изменений мягких тканей лица, а также для коррекции формы и объема молочных желез как в случаях их реконструкции, так и сугубо по эстетическим показаниям.

Ряд авторов сообщает о случаях слепоты, острого нарушения мозгового кровообращения, некроза участка кожи в области хирургического вмешательства при проведении ЛФ лица. В частности, приводятся сведения о случаях потери зрения пациентами после выполнения им липофилинга. Как правило, данное осложнение 
развивалось при введении АЖТ в мягкие ткани назальной и периорбитальной областей посредством острых игл [64-68].

Еще одним осложнением ЛФ лица оказывается некроз кожи в месте введения аутологичной жировой ткани. По всей видимости, это происходит по причине эмболизации мелких ветвей артерий, кровоснабжающих покровные ткани в месте хирургического вмешательства [69].

Наиболее распространенным осложнением ЛФ, выполняемого с целью коррекции формы и объема молочных желез пациенток, является формирование в послеоперационном периоде жировых кист разных размеров. Приводятся данные о трех случаях выявления жировых кист после увеличения молочных желез посредством ЛФ, потребовавших выполнения хирургических вмешательств по их удалению в целом с положительным исходом [70]. Обогащение трансплантируемой жировой ткани СК позволяет предотвратить эти негативные результаты, снизить вероятность повторных хирургических вмешательств, направленных на удаление кистозных образований из ЖТ, сформировавшихся в ткани молочных желез после их ЛФ [5].

Наиболее тяжелыми и опасными компликациями липофилинга являются развитие острого нарушения мозгового кровообращения, потеря зрения. Для предупреждения подобных негативных явлений при трансплантации АЖТ следует применять тупоконечные канюли, а не острые иглы, в силу технических особенностей характеризующиеся большими возможностями для перфорации стенки артерий. Кроме того, предельный объем шприца для аутоадипотрансплантации в мягкие ткани лица не должен превышать 1 мл. Объем жировой ткани, имплантируемой с каждым проходом канюли при ЛФ лица, не должен превышать 0,1 мл, а в параорбитальной области должен составлять менее 0,033 или 0,02 мл. Очевидно также, что стенку спазмированной артерии перфорировать труднее, поэтому введение АЖТ в мягкие ткани лица должно сопровождаться предварительными инъекциями в область планируемой коррекции раствора местного анестетика с добавлением эпинефрина.

Разработка и внедрение клеточных технологий в клинической хирургии обнадеживает. Возможности клеточной терапии очевидны, так же как необходим и поиск путей модернизации подходов к выполнению ЛС и ЛФ, поскольку сегодня СК из ЖТ применяются врачами для лечения такой тяжелой общесоматической патологии, как сахарный диабет, облитерирующие заболевания артерий конечностей, а отдельные исследования направлены на улучшение функции сердца в группе пациентов, страдающих хронической сердечной недостаточностью. Безусловно, возможности применения СК, выделяемых из аутологичной ЖТ, в клинической практике тесно связаны с необходимостью сбора биологического материала для изоляции клеток, осуществляемого преимущественно при липосакции с его последующей имплантацией, осуществляемой при липофилинге.

\section{Заключение}

Изучение источников научной литературы позволяет считать, что получение биологического материала для выделения культуры СК при липосакции имеет ряд особенностей по сравнению с ЛС, выполняемой по сугубо косметическим показа- 
ниям. Прежде всего при липосакции для выделения культуры СК жировая ткань чаще всего собирается у пациентов, страдающих в той или иной степени выраженности и компенсированности сопутствующей общесоматической патологией; поэтому обследование пациентов перед операцией должно быть предельно тщательным, а коморбидные состояния необходимо адекватно скорректировать при комплексном терапевтическом сопровождении таких больных. Особое внимание следует уделять профилактике осложнений как на этапе сбора биологического материала для выделения СК, так и при его трансплантации путем липофилинга.

Возможности применения клеточных технологий в клинической практике сегодня обнадеживают в том плане, что многие проблемы пластической и реконструктивной хирургии можно решить, используя свойства СК. Однако анализ данных многих авторов позволяет заключить, что даже при минимальной инвазивности хирургических вмешательств на этапах осуществления КСЛ эти операции все же характеризуются определенной вероятностью развития осложнений, даже в случаях их выполнения соматически здоровым пациентам по эстетическим показаниям. Тем не менее, при соблюдении ряда правил выполнения операций с применением клеточных культур в настоящее время перспективы успешного применения технологий клеточной терапии все же существуют и отрицать их нельзя. Для предупреждения осложнений КСЛ в послеоперационном периоде необходимы строгое следование протоколам проведения хирургических вмешательств, тщательный контроль соблюдения персоналом правил асептики и антисептики, комплексная профилактика тромботических осложнений независимо от объема операции, целенаправленная медикаментозная коррекция сопутствующей общесоматической патологии пациента. Знание и реализация комплекса мероприятий по предупреждению негативных последствий трансплантации аутологичной жировой ткани, обогащенной культурой стволовых клеток, несомненно, должны способствовать сокращению числа послеоперационных осложнений в случаях применения клеточной терапии в пластической и реконструктивной хирургии. Последнее обеспечит более широкое внедрение инновационных технологий регенеративной медицины в клиническую практику.

\section{References}

1. Flynn T., Coleman W. History of liposuction. Dermatol. Surg., 2000, no. 26, pp. 515-520.

2. Illouz Y. Body contouring by lipolysis: a 5-year experience with over 3000 cases. Plast. Reconstr. Surg., 1983, no. 72, pp. 591-597.

3. Frank S. J., Flusberg M., Friedman S., Swinburne N., Sternschein M., Wolf E. L., Stein M.W. CT appearance of common cosmetic and reconstructive surgical procedures and their complications. Clin. Radiol., 2013, no. 68, pp. 72-78.

4. Stephan P. J., Kenkel J.M. Updates and advances in liposuction. Aesthet. Surg. J., 2010, no. 30, pp. 83-97.

5. Zuk P. A., Zhu M., Mizuno H., Huang J., Futrell J. W., Katz A. J., Benhaim P., Lorenz H. P., Hedrick M. H. Multilineage cells from human adipose tissue: implications for cell-based therapies. Tissue Eng., 2001, vol. 7, no. 2, pp. 211-226.

6. Yoshimura K., Sato K., Aoi N. et al. Cell-assisted lipotransfer for cosmetic breast augmentation: supportive use of adipose-derived stem/stromal cells. Aesthetic Plast. Surg., 2008, vol. 32, no. 1, pp. 48-55.

7. Castro-Govea Y., De La Garza-Pineda O., Lara-Arias J., Chacón-Martínez H., Mecott-Rivera G., Salazar-Lozano A., Valdes-Flores E. Cell-assisted lipotransfer for the treatment of Parry-Romberg syndrome. Arch. Plast. Surg., 2012, vol. 39, no. 6, pp. 659-662. 
8. Lee S. K., Kim D. W., Dhong E. S., Kurita M., Inoue K., Suga H., Eto H., Kato H., Hirohi T., Harii K. Facial soft tissue augmentation using autologous fat mixed with stromal vascular fraction. Arch. Plast. Surg., 2012, vol. 39, no. 5, pp. 534-539.

9. Yoshimura K., Sato K., Aoi N., et al. Cell-assisted lipotransfer for facial lipoatrophy: efficacy of clinical use of adipose-derived stem cells. Dermatol. Surg., 2008, vol. 34, no. 9, pp. 1178-1185.

10. Yoshimura K., Asano Y., Aoi N., Kurita M., Oshima Y., Sato K., Inoue K., Suga H., Eto H., Kato H., Harii K. Progenitor-enriched adipose tissue transplantation as rescue for breast implant complications. Breast J., 2010, no. 16, pp. 169-175.

11. Zhou Y., Wang J., Li H., Liang X., Bae J., Huang X., Li Q. Efficacy and safety of cell-assisted lipotransfer: A systematic review and meta-analysis. Plast. Reconstr. Surg., 2016, vol. 137, no. 1, pp. 44-57.

12. Lehnhardt M., Homann H. H., Daigeler A., Hauser J., Palka P., Steinau H. U. Major and lethal complications of liposuction: a review of 72 cases in Germany between 1998 and 2002. Plast. Reconstr. Surg., 2008, no. 121, pp. 396-403.

13. Kim Y.H., Cha S. M., Naidu S., Hwang W. J. Analysis of postoperative complications for superficial liposuction: a review of 2398 cases. Plast. Reconstr. Surg., 2011, no. 127, pp. 863-871.

14. Stephan P. J., Kenkel J. M. Updates and advances in liposuction. Aesthet. Surg. J., 2010, no. 30, pp. 83-97.

15. Grazer F. M., de Jong R.H. Fatal outcomes from liposuction: census survey of cosmetic surgeons. Plast. Reconstr. Surg., 2000, no. 105, pp. 436-448.

16. Rao B. R., Fly S. F., Hoffman R. S. Deaths related to liposuction. The New England Journal of Medicine, 1999, vol. 340, no. 19, pp. 1471-1475.

17. Vongpaisarnsin K., Tansrisawad N., Hoonwijit U., Jongsakul T. Pseudomonas aeruginosa septicemia causes death following liposuction with allogenic fat transfer and gluteal augmentation. Int. J. Legal Med., 2014. doi 10.1007/s00414-014-1056-3.

18. Ovrebo K.K., Grong K., Vindenes H. Small intestinal perforation and peritonitis after abdominal suction lipoplasty. Ann. Plast. Surg., 1997, vol. 38, no. 6, pp. 642-644.

19. Talmor M., Hoffman L. A., Lieberman M. Intestinal perforation after suction lipoplasty: a case report and review of the literature. Ann. Plast. Surg., 1997, vol. 38, no. 2, pp. 169-172.

20. Mallappa M., Rangaswamy M., Badiuddin M.F. Small intestinal perforation and peritonitis after liposuction. Aesth. Plast. Surg., 2007, no. 31, pp. 589-592.

21. Coronado-Malagón M., Tauffer-Carrion L. T. Jejunal perforation after abdominal liposuction, bilateral breast augmentation and facial fat grafting. Can. J. Plast. Surg., 2012, vol. 20, no. 3, pp. 197-198.

22. Sterodimas A., Boriani F., Magarakis E., Nicaretta B., Pereira L.H., Illouz Y. G. Thirtyfour years of liposuction: past, present and future. Eur. Rev. Med. Pharmacol. Sci., 2012, no. 16, pp. 393-406.

23. Di Candia M., Charles M. Malata aesthetic and functional abdominal wall reconstruction after multiple bowel perforations secondary to liposuction. Aesth. Plast. Surg., 2011, no. 35, pp. 274-277.

24. Raman S. R., Pokala N., Cosgrove J., Jamil Z. Colocutaneous fistula after suction lipoplasty: case report and literature review. Ann. Plast. Surg., 2010, vol. 64, no. 4, pp. 503-505.

25. Lim H., Kim H. J., Cho Y.S. Active bleeding in abdominal wall developing after liposuction. Emerg. Med. J., 2008, no. 25, p. 814.

26. Dixit V. V., Wagh M. S. Unfavourable outcomes of liposuction and their management. Indian J. Plast. Surg., 2013, no. 46, pp. 377-392.

27. You J., Chung Y., Baek S., Chung S. P., Kim M.-J. Imaging findings of liposuction with an emphasis on postsurgical complications. Korean J. Radiol., 2015, vol. 16, no. 6, pp. 1197-1206.

28. Beeson W.H., Slama T.G., Beeler R. T., Rachel J.D., Picerno N. A. Group A streptococcal fasciitis after submental tumescent liposuction. Arch. Facial Plast. Surg., 2001, no. 3, pp. 277-279.

29. Heitmann C., Czermak C., Germann G. Rapidly fatal necrotizing fasciitis after aesthetic liposuction. Aesth. Plast. Surg., 2000, no. 24, pp. 344-347.

30. Giannella M., Pistella E., Perciaccante A., Venditti M. Soft tissue infection caused by Mycobacterium chelonae following a liposculpture and lipofilling procedure. Ann. Ital. Med. Int., 2005, no. 20, pp. 245-247.

31. Fisher E. J., Gloster H. M. Jr. Infection with Mycobacterium abscessus after Mohs micrographic surgery in an immunocompetent patient. Dermatol. Surg., 2005, vol. 31, no. 7, pp. 790-794.

32. Meyers H., Brown-Elliott B. A., Moore D., Curry J., Truong C., Zhang Y., Wallace Jr. R. J. An outbreak of Mycobacterium chelonae infection following liposuction. Clin. Infect. Dis., 2002, no. 34, pp. 1500-1507.

33. Murillo J., Torres J., Ríos-Fabra A., Irausquin E., Istúriz R., Guzmán M., Castro J., Rubino L., Cordido M. Skin and wound infection by rapidly growing mycobacteria: An unexpected complication of liposuction and liposculpture. Arch. Dermatol., 2000, no. 136, pp. 1347-1352. 
34. Fayad L. M., Carrino J. A., Fishman E. K. Musculoskeletal infection: role of CT in the emergency department. Radiographics, 2007, no. 27, pp. 1723-1736.

35. Shin S. U., Lee W., Park E. A., Shin C. I., Chung J.W., Park J.H. Comparison of characteristic CT findings of lymphedema, cellulitis, and generalized edema in lower leg swelling. Int. J. Cardiovasc. Imaging, 2013, no. 29, pp. 135-143.

36. Chung Y.E., Kim Y.E., Park I., You J.S. Subcutaneous emphysema after carbon dioxide injection. J. Emerg. Med., 2014, no. 47, pp. 89-90.

37. Heinze S., Puschel K., Tsokos M. Necrotizing fasciitis with fatal outcome: a report of two cases. Forensic Sci. Med. Pathol., 2011, no. 7, pp. 278-282.

38. Sherman J.E., Fanzio P.M., White H., Leifer D. Blindness and necrotizing fasciitis after liposuction and fat transfer. Plast. Reconstr. Surg., 2010, vol. 126, no. 4, pp. 1358-1363.

39. Gonzáles A., Marin de la Cruz D., Palao Doménech R., Barret Nerin J.P. Necrotizing fasciitis after liposuction. Acta Chir. Plast., 2007, vol. 49, no. 4, pp. 99-102.

40. Nagelvoort R. W., Hulstaert P. F., Kon M., Schuurman A. H. Necrotising fasciitis and myositis as serious complications after liposuction. Ned. Tijdschr. Geneeskd., 2002, vol. 146, no. 50, pp. 2430-2435.

41. Heitmann C., Czermak C., Germann G. Rapidly fatal necrotizing fasciitis after aesthetic liposuction. Aesthetic Plast. Surg., 2000, vol. 24, no. 5, pp. 344-347.

42. Umeda T., Ohara H., Hayashi O., Ueki M., Hata Y. Toxic shock syndrome after suction lipectomy. Plast. Reconstr. Surg., 2000, vol. 106, no. 1, pp. 204-209.

43. Barillo D. J., Cancio L. C., Kim S. H., Shirani K.Z., Goodwin C. W. Fatal and near-fatal complications of liposuction. South Med. J., 1998, vol. 91, no. 5, pp. 487-492.

44. Gibbons M.D., Lim R. B., Carter P.L. Necrotizing fasciitis after tumescent liposuction. Am. Surg., 1998, vol. 64, no. 5, pp. 458-460.

45. Chaudhry A. A., Baker K. S., Gould E. S., Gupta R. Necrotizing fasciitis and its mimics: what radiologists need to know. Am. J. Roentgenol., 2015, no. 204, pp. 128-139.

46. Hakkarainen T. W., Kopari N. M., Pham T.N., Evans H. L. Necrotizing soft tissue infections: review and current concepts in treatment, systems of care, and outcomes. Curr. Probl. Surg., 2014, no. 51, pp. 344-362.

47. Geerts W.H., Heit J. A., Clagett G. P., Heit J. A., Samama C. M., Lassen M. R., Colwell C. W. Prevention of venous thromboembolism. Chest, 2001, vol. 119, no. 1, pp. 132-175.

48. Uemura K., Kikuchi Y., Shintani-Ishida K., Nakajima M., Yoshida K. A fatal case of post-operative pulmonary thromboembolism with cosmetic liposuction. J. Clin. Forensic Med., 2006, vol. 13, no. 1, pp. 41-43.

49. Esmon C. T. Basic mechanisms and pathogenesis of venous thrombosis. Blood Rev., 2009, no. 23, pp. 225-229.

50. Gravante G., Araco A., Sorge R., Araco F., Nicoli F., Caruso R., Langiano N., Cervelli V. Pulmonary embolism after combined abdominoplasty and flank liposuction: a correlation with the amount of fat removed. Ann. Plast. Surg., 2008, vol. 60, no. 6, pp. 604-608.

51. Conkbayır C., Kenan S., Emiroğlu O. Massive pulmonary thromboembolism after abdominoplasty and liposuction. Arch. Turk. Soc. Cardiol., 2011, vol. 39, no. 5, pp. 410-413.

52. Jurgens W. J., Oedayrajsingh-Varma M. J., Helder M. N., Zandiehdoulabi B., Schouten T. E., Kuik D. J., Ritt M. J., van Milligen F. J. Effect of tissue-harvesting site on yield of stem cells derived from adipose tissue: implications for cell-based therapies. Cell Tissue Res., 2008, vol. 332, no. 3, pp. 415-426.

53. Schipper B. M., Marra K. G., Zhang W., Donnenberg A. D., Rubin J.P. Regional anatomic and age effects on cell function of human adipose-derived stem cells. Ann. Plast. Surg., 2008, vol. 60, no. 5, pp. 538544 .

54. Lee H. C., An S. G., Lee H. W., Park J. S., Cha K. S., Hong T. J., Park J.H., Lee S. Y., Kim S. P., Kim Y. D., Chung S. W., Bae Y. C., Shin Y. B., Kim J.I., Jung J.S. Safety and effect of adipose tissue-derived stem cell implantation in patients with critical limb ischemia: a pilot study. Circ. J., 2012, no. 76, pp. 1750-1760.

55. Mojallal A. Influence of negative pressure when harvesting adipose tissue on cell yield of the stromal-vascular fraction. Biomed. Mater. Eng., 2008, vol.18, no. 4-5, pp. 193-197.

56. Matsumoto D. Influences of preservation at various temperatures on liposuction aspirates. Plast. Reconstr. Surg., 2007, vol. 120, no. 6, pp. 1510-1517.

57. Boquest A. C. Isolation of stromal stem cells from human adipose tissue. Methods Mol. Biol., 2006, no. 325, pp. 35-46.

58. Dubois S. G. Isolation of human adipose-derived stem cells from biopsies and liposuction specimens. Methods Mol. Biol., 2008, no. 449, pp. 69-79.

59. Aronowitz J. A., Ellenhorn J. D. Adipose stromal vascular fraction isolation: a head-to-head comparison of four commercial cell separation systems. Plast. Reconstr. Surg., 2013, vol. 132, no. 6, pp. $932-$ 939. 
60. Kirkpatrick C. J. Comparative effects of trypsin, collagenase and mechanical harvesting on cell membrane lipids studied in monolayer-cultured endothelial cells and a green monkey kidney cell line. Biochim. Biophys. Acta., 1985, vol. 846, no. 1, pp. 120-126.

61. Pilgaard L. Comparative analysis of highly defined proteases for the isolation of adipose tissue-derived stem cells. Regen. Med., 2008. vol. 3, no. 5, pp. 705-715.

62. Domenis R. Adipose tissue derived stem cells: in vitro and in vivo analysis of a standard and three commercially available cell-assisted lipotransfer techniques. Stem Cell Res. Ther., 2015. vol. 6, no. 1, p. 2.

63. Yu N.Z., Huang J.Z., Zhang H., Wang Y., Wang X.-J., Zhao R., Bai M., Long X. A Systemic Review of Autologous fat grafting survival rate and related severe complications. Chin. Med. J., 2015, vol. 128, no. 9, pp. 1245-1251.

64. Teimourian B. Blindness following fat injection. Plast. Reconstr. Surg., 1988, no. 82, p. 361.

65. Dreizen N. G., Framm L. Sudden unilateral visual loss after autologous fat injection into the glabellar area. Am. J. Ophthalmol., 1989, no. 107, pp. 85-87.

66. Egido J. A., Arroyo R., Marcos A., Jiménez-Alfaro I. Middle cerebral artery embolism and unilateral visual loss after autologous fat injection into the glabellar area. Stroke, 1993, no. 24, pp. 615-616.

67. Lee D. H., Yang H. N., Kim J. C., Shyn K. H. Sudden unilateral visual loss and brain infraction after autologous fat injection into the nasolabial groove. Br. J. Ophthalmol., 1996, no. 80, pp. 1026-1027.

68. Feinendegen D. L., Baumgartner R. W., Schroth G., Mattle H.P., Tschopp H. Middle cerebral artery occlusion and ocular fat embolism after autologous fat injection in the face. J. Neurol., 1998, no. 245, pp. 53-54.

69. Danesh-Mayer H. V., Savino P. J., Sergott R. C. Case reports and small case series: ocular and cerebral ischemia following facial injection of autologous fat. Arch. Ophthalmol., 2001, no. 19, pp. 777-778.

70. Mineda K., Kuno S., Kato H., Kinoshita K., Doi K., Hashimoto I., Nakanishi H., Yoshimura K. Chronic inflammation and progressive calcification as a result of fat necrosis: the worst outcome in fat grafting. Plast. Reconstr. Surg., 2014, no. 133, pp. 1064-1072.

Для цитирования: Романенков Н.С., Мовчан К.Н. Негативные эффекты трансплантации аутологичной жировой ткани, обогащенной культурой стволовых клеток (обзор литературы) // Вестник СПбГУ. Медицина. 2017. Т. 12. Вып. 4. С. 326-339.

https://doi.org/ 10.21638/11701/spbu11.2017.403

For citation: Romanenkov N.S., Movchan K. N. Adipose derived stem cells transplantation negative effects (review). Vestnik SPbSU. Medicine, 2017, vol. 12, issue 4, pp. 326-339.

https://doi.org/10.21638/11701/spbu11.2017.403

Статья поступила в редакцию 29 июня 2017 г.

Статья принята в печать 11 сентября 2017 г.

Контактная информация:

Романенков Николай Сергеевич - кандидат медицинских наук; nickrom@inbox.ru

Мовчан Константин Николаевич - доктор медицинских наук, профессор;

MovchanK@miac.zdrav.spb.ru

Romanenkov NikolayS. — PhD; nickrom@inbox.ru

Movchan Konstantin N. - MD, Professor; MovchanK@miac.zdrav.spb.ru 